\title{
Epigenetic modifications and their relation to caste and sex determination and adult division of labor in the stingless bee Melipona scutellaris
}

\author{
Carlos A.M. Cardoso-Júnior ${ }^{1,2}$, Patrícia Tieme Fujimura ${ }^{1}$, Célio Dias Santos-Júnior ${ }^{3}$, Naiara Araújo Borges ${ }^{1}$, \\ Carlos Ueira-Vieira ${ }^{1}$, Klaus Hartfelder ${ }^{2}$, Luiz Ricardo Goulart ${ }^{1}$ and Ana Maria Bonetti ${ }^{1}$ \\ ${ }^{1}$ Departamento de Genética e Bioquímica, Universidade Federal de Uberlândia, Uberlândia, MG, Brazil. \\ ${ }^{2}$ Departamento de Biologia Celular e Molecular e Bioagentes Patogênicos, Faculdade de Medicina de \\ Ribeirão Preto, Universidade de São Paulo, Ribeirão Preto, SP, Brazil. \\ ${ }^{3}$ Departmento de Genética e Evolução, Universidade Federal de São Carlos, São Carlos, SP, Brazil.
}

\begin{abstract}
Stingless bees of the genus Melipona, have long been considered an enigmatic case among social insects for their mode of caste determination, where in addition to larval food type and quantity, the genotype also has a saying, as proposed over 50 years ago by Warwick E. Kerr. Several attempts have since tried to test his Mendelian two-loci/two-alleles segregation hypothesis, but only recently a single gene crucial for sex determination in bees was evidenced to be sex-specifically spliced and also caste-specifically expressed in a Melipona species. Since alternative splicing is frequently associated with epigenetic marks, and the epigenetic status plays a major role in setting the caste phenotype in the honey bee, we investigated here epigenetic chromatin modification in the stingless bee Melipona scutellaris. We used an ELISA-based methodology to quantify global methylation status and western blot assays to reveal histone modifications. The results evidenced DNA methylation/demethylation events in larvae and pupae, and significant differences in histone methylation and phosphorylation between newly emerged adult queens and workers. The epigenetic dynamics seen in this stingless bee species represent a new facet in the caste determination process in Melipona bees and suggest a possible mechanism that is likely to link a genotype component to the larval diet and adult social behavior of these bees.
\end{abstract}

Keywords: DNA methylation, histone modification, caste development, social bees, genetic caste determination.

Received: August 31, 2016; Accepted: January 12, 2017.

\section{Introduction}

Studies on caste determination in bees have largely benefited from the availability of a well annotated genome sequence from Apis mellifera (The Honey Bee Genome Sequencing Consortium, 2006). This directed the focus to a key issue, the role and function of nutrient sensing pathways as connectors between the differential nutrition of the queen and worker larvae and the endocrine signals related to differential gene expression (Hartfelder et al., 2015). In comparison, frustratingly little progress has been made for stingless bees with respect to understanding how caste is determined since this question has last been comprehensively reviewed (Hartfelder et al., 2006).

While in most highly eusocial bees, wasps and ants, the genome of a single individual is capable of being nutritionally driven to express one of the alternative phenotypes

Send correspondence to Klaus Hartfelder. Departamento de Biologia Celular e Molecular e Bioagentes Patogênicos, Faculdade de Medicina de Ribeirão Preto, Universidade de São Paulo, Av. Bandeirantes 3900, 14049-900 Ribeirão Preto, SP, Brazil. E-mail: klaus@fmrp.usp.br (typically the queen and worker morph, but also additional worker morphs in ants), caste fate in the genus Melipona, as well as in certain ants, such as Pogonomyrmex, is biased by the genotype (for a review see Corona et al., 2016). In stingless bees of the genus Melipona, queens, workers and males emerge from brood cells of the same size with no differences in the quantity of the diet supplied to the larvae (Kerr, 1946, 1950; Beig et al., 1985). The still most accepted mechanistic hypothesis of caste determination in Melipona is the interaction of genetic and environmental factors that jointly influence juvenile hormone $(\mathrm{JH})$ biosynthesis (Velthuis, 1976; Bonetti et al., 1995). According to this hypothesis, double heterozygosity at two not yet identified loci, coupled with an adequate food supply would result in high levels of $\mathrm{JH}$ production, and under optimal colony conditions, this predicted mechanism could explain the observed 3:1 worker to queen ratio in newly emerged female brood (Kerr and Nielsen, 1966).

The two loci/two alleles hypothesis with classic Mendelian segregation as the genetic basis of caste determination in the genus Melipona (Kerr, 1950) has a long history of controversy (see Hartfelder et al., 2006), especially be- 
cause most of the issues raised fall into the debate of developmental (mechanistic) factors $v s$. evolutionary (ultimate) causes. In Melipona, neither the queen nor the brood-tending workers have apparently control over the caste fate of the brood, which is raised in cells of equal size and practically on the same quantity of larval food, in complete contrast to the nutritional caste determination in the honey bee (for a recent review see Hartfelder et al., 2015). Hence, on theoretical grounds, it was proposed that the brood should have the potential to self-determine its proper caste fate, and modeling of the inclusive fitness of Melipona females actually predicted an optimum queen-emergence frequency of $20 \%$ in the female brood of a colony headed by a single-mated queen (Wenseleers et al., 2003; Wenseleers and Ratnieks, 2004). Clearly, this is very close to the ratio observed and postulated under the Mendelian genetics two loci/two alleles hypothesis. Nonetheless, there is now evidence that a specific compound in larval food, geraniol, may have a queen-fate inducing effect in Melipona bees (Jarau et al., 2010).

The discussion on the mechanistic and, especially so, the molecular basis of caste determination in the stingless bee genus Melipona has recently gained important insights from the molecular mechanisms underlying sex determination in the honey bee. The feminizer (fem) gene, which is sex-specifically spliced in bees (Biewer et al., 2015), is not only sex-specifically spliced during embryonic development in relation to sex determination, but was also evidenced to be sex- and caste-specifically expressed during late larval development in Melipona interrupta (Brito et al., 2015). Furthermore, these same authors showed that fem is also regulated by JH during the larval stage critical for caste differentiation. Though unlikely to be one of the actual two loci for genetic caste determination in Melipona bees, as proposed by Kerr (1950), the fem gene is nonetheless the first bona fide candidate gene involved in caste development. Nonetheless, the integration between JH and the gene regulatory networks that drive differential gene expression related to caste development in stingless bees is still an open question.

Recently, the Melipona quadrifasciata genome has been fully sequenced as part of a comparative genomic study on 10 bee species (Kapheim et al., 2015). One remarkable conclusion from this study was, that as sociality gets more complex, the bees present a higher number of potential methylation sites on gene bodies. Hence, the increase in $\mathrm{CpG}$ sites in the bee genomes concurrent with the social level should be of broad significance, especially so in the light of the functional importance of DNA methylation in honey bee caste development (Kucharski et al., 2008), and could present an important factor within the genetic determination of caste in the stingless bee genus Melipona.

DNA methylation and post-translational histone modifications have been extensively investigated in chromatin reorganization of many vertebrates (Gabor Miklos and Maleszka, 2011). However, for invertebrates, epigenetic modifications and their functional roles in the control of gene expression are still controversial issues. This is largely so because among the two main invertebrate model systems the nematode Caenorhabditis elegans does not present any DNA methylation at all (Gabor Miklos and Maleszka, 2011), and the genome of the fruit fly, Drosophila melanogaster, only encodes a DNA methyltransferase 2 homolog, which has no in vitro activity and is not capable of methylating CpG dinucleotides (Tweedie et al., 1999; Lyko et al., 2000; Kunert et al., 2003). Furthermore, a methylomics study on the mosquito Aedes aegypti could not detect a defined DNA methylation profile, and RNA bisulfite sequencing revealed that methylation in tRNAs may actually be implicated in dengue virus replication (Falckenhayn et al., 2016). In contrast, the red flower beetle, Tribolium castaneum, shows DNA methylation (Feliciello et al., 2013), and its genome has the potential to encode at least two DNA methyltransferases (DNMTs), a DNMT1 and a DNMT2 (Tribolium Genome Sequencing Consortium et al., 2008).

Within the order Hymenoptera, DNA methylation has become an important topic once a complete set of DNA methyltransferases (DNMTs) was evidenced in the sequenced genome of the honey bee (Wang et al., 2006), and the functional importance of DNMT3 in caste phenotype determination was convincingly demonstrated by Kucharski et al. (2006). Subsequent studies then revealed extensive differential DNA methylation in honey bees related to caste development (Foret et al., 2012) and learning and memory formation (Lockett et al., 2010). Furthermore, a direct association between differential DNA methylation and alternative splicing was put in evidence (Foret et al., 2012; LiByarlay et al., 2013). Several histone post-translation modifications have also been identified in honey bees (Dickman et al., 2013). Similar findings on epigenetic chromatin modification, especially DNA methylation, was also reported for several species of ants (Bonasio et al., 2012; Bonasio, 2014; Alvarado et al., 2015; Glastad et al., 2015), leading to infer that DNA methylation is associated with and plays an important role in caste and life cycle regulation across social Hymenoptera (Weiner et al., 2013).

Here we hypothesize that an epigenetically modulated chromatin state may affect caste fate in Melipona bees, and we investigated this question in a pilot study on Melipona scutellaris. Our goals were to obtain evidence for the presence of an active DNA methylation system and post-translational histone $\mathrm{H} 3$ tail modifications in these bees, and to see how the resultant epigenetic states may be differentially modulated and related to sex and caste development and to adult behavioral states. 


\section{Materials and Methods}

\section{Bees}

Melipona scutellaris larvae, pupae, newly emerged queens, males and workers, as well as adult workers performing different roles (nurses and foragers) were collected from colonies maintained in the meliponary of the Federal University of Uberlândia. The classification of developmental stages used here is described in Dias et al. (2001) and Vieira et al. (2008)._After sampling, the bees were immediately frozen in liquid nitrogen and stored at $-80{ }^{\circ} \mathrm{C}$ until use.

\section{DNA extraction and methylated cytidine quantification}

We quantified the levels of global DNA methylation using an ELISA-based assay following the protocols established for aphids (Ayyanath et al., 2014) and the honey bee (Shi et al., 2011). This methodology has been successfully employed to identify DNA methylation differences without requiring a known genome sequence (Olkhov-Mitsel and Bapat, 2012). Briefly, genomic DNA from individual bees of each developmental stage was extracted by the CTAB method (Chen et al., 2010) and quantified using a NanoDrop Spectrophotometer (ND-1000, Thermo Scientific). The content of methylated cytidine bases was assessed by means of the EIA DNA Methylation kit (Cayman Chemicals, Ann Arbor, MI, USA). Two dilutions were used to calculate the respective OD values by regression against a standard curve prepared as recommended by the manufacturer. Since the larval OD values exceeded the linear range of the standard curve, their DNA methylation content is reported semiquantitatively only, as highly methylated DNA. Each age group or sample type is represented by three individual bees as biological replicates.

\section{Histone acid extraction and western blot analysis}

Histone post-translational modifications were investigated by western blot analysis of acid extracted histones from five individual bees of each sample type. The acid extraction followed the Abcam protocol (http://www.abcam.com/proto-

cols/histone-extraction-protocol-for-western-blot).

Briefly, the bees were macerated in liquid nitrogen and incubated for $10 \mathrm{~min}$ on ice with Triton extraction buffer (TEB) consisting of PBS containing $0.5 \%$ Triton X100 (v/v), $2 \mathrm{mM}$ phenylmethylsulfonyl fluoride (PMSF) and $0.02 \%(\mathrm{w} / \mathrm{v})$ sodium azide $\left(\mathrm{NaN}_{3}\right)$. After centrifugation at $2,000 \times \mathrm{g}$ at $4{ }^{\circ} \mathrm{C}$ the supernatant was discarded and the nuclear pellet washed in $1 \mathrm{~mL}$ of TEB. Following a second centrifugation step, the pellet was resuspended in $0.2 \mathrm{~N}$ $\mathrm{HCl}$ overnight for acid extraction of histones at $4{ }^{\circ} \mathrm{C}$. The supernatant containing acid-soluble proteins, including acidic histones, was dialyzed twice against acetic acid for 1 $\mathrm{h}$ and 3 times against distilled water ( $1 \mathrm{~h}, 3 \mathrm{~h}$ and overnight) according to Di Paola et al. (2012). The dialyses were performed with 1000 MWCO Spectra/Por ${ }^{\mathrm{TM}}$ membranes (Spectrum Laboratories, Rancho Dominguez, CA). The protein concentrations of the histone extracts were determined by Bradford assay, following the manufacturer's protocol (Bio-Rad, Hercules, CA, USA).

Fifty-two micrograms of histone protein extract were separated by $17.5 \%$ SDS-PAGE followed by electrophoretic transfer onto Hybond ${ }^{\mathrm{TM}}$ ECL $0.2 \mu \mathrm{M}$ nitrocellulose membranes (Amersham, Bucks, UK) overnight at $80 \mathrm{~mA}$. The membranes were blocked with $3 \%$ non-fat milk diluted in PBS for $1 \mathrm{~h}$, incubated with primary antibodies for $3 \mathrm{~h}$, washed three times with PBS, and incubated with secondary antibodies for $1 \mathrm{~h}$. Subsequently, the membranes were washed three times with PBS before incubation with ECL Western Blot Detection Reagent (Amersham). The immunoreactive bands were detected with a GBX detection reagent (Kodak) and Hyperfilm ${ }^{\mathrm{TM}}$ ECL (Amersham). The following antibodies were used: anti-H3T3-P (Cell Signaling Technology, Danvers, MA), anti-H3K4-Me (Cell Signaling), anti-H2B (Abcam, Cambridge, UK) and HRPconjugated anti-rabbit IgG (Sigma-Aldrich, Saint Louis, $\mathrm{MO}$ ) in appropriate replicates and using the manufacturers suggestions for ideal dilutions. Band intensity was quantified using Image $J^{\mathbb{R}}$ software $1.47 \mathrm{v}$. The data were normalized by the control band intensity. The sample analyses were replicated three times.

\section{Statistical analysis}

For the DNA methylation assays, the average differences between larval stages, caste and sex of pupae and adults were analyzed by a Kruskal-Wallis test followed by Dunn's post-hoc tests. A one-tailed Mann-Whitney test was used to compare average differences between pupae and adult individuals. For the histone modification analyses, the western blot image data were confirmed for normality by a Kolmogorov-Smirnov test before running a two-tailed unpaired Student's $t$-test. All statistical analyses were performed with GraphPad Prism 5 (GraphPad Software Inv., La Jolla, CA, USA), with a significance value set at $\mathrm{p}<0.05$.

\section{Results and Discussion}

\section{Global DNA methylation levels in Melipona scutellaris sexes and castes}

The content of methylated DNA of specimens of the stingless bee $M$. scutellaris was calculated for pupae and adult bees of both sexes and castes. For larvae, only a general level of DNA methylation could be assessed, because it is not possible to distinguish sex and caste in larval stages (Amaral et al., 2010).

The DNA of larvae of Melipona scutellaris turned out to be strongly hypermethylated (Figure 1A), followed by a fast demethylation event during the larval-pupal transition. 


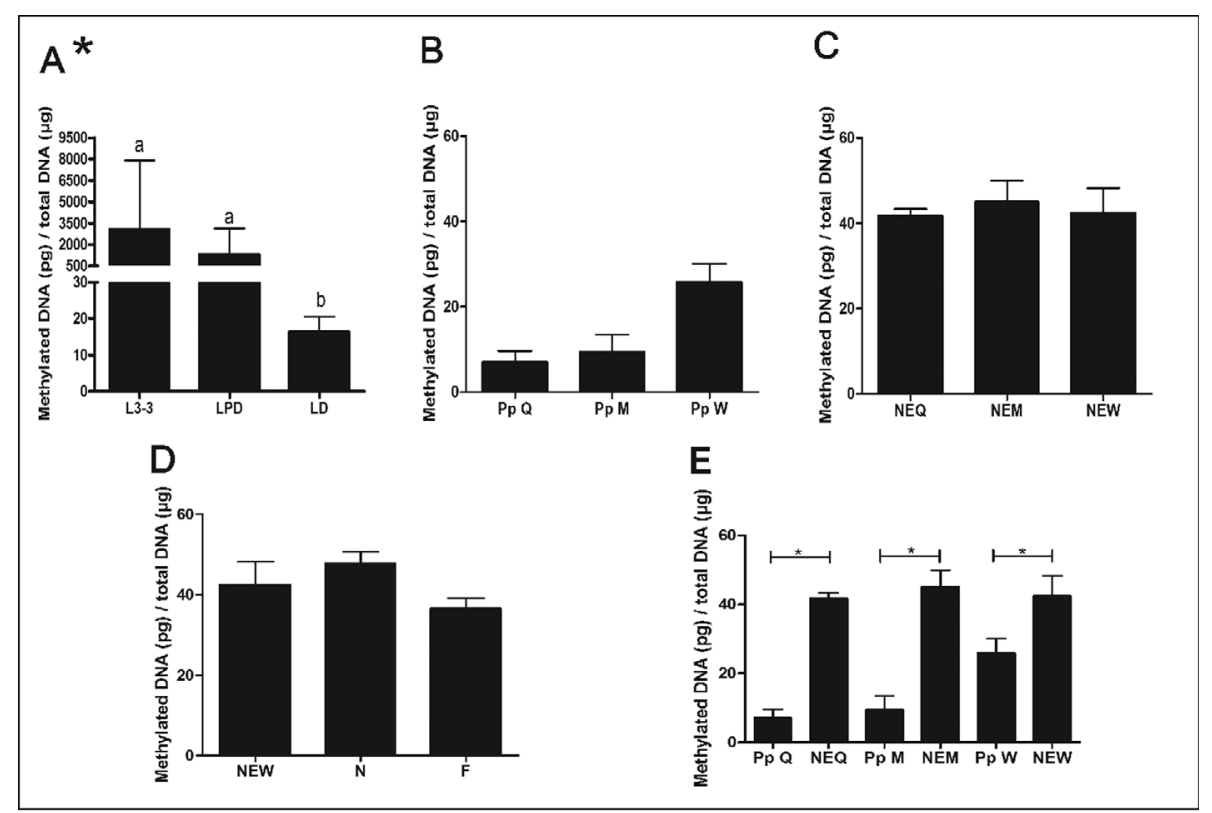

Figure 1 - Quantification of methylated cytidine content in the genomic DNA of Melipona scutellaris analyzed by ELISA. (A) Quantification of methylated DNA of larvae, (B) pupae, (C) newly emerged individuals, and (D) adult workers. In (E) the methylated cytidine content is shown for queens, workers and males, contrasting pupae against newly emerged individuals. L3-3 = larva of the third stage in the third instar; $\mathrm{LPD}=$ pre-defecating larva; $\mathrm{LD}=$ defecating larva; $\mathrm{PpQ}=$ pink-eyed queen pupa; $\mathrm{PpM}=$ pink-eyed male pupa; $\mathrm{PpW}=$ pink-eyed worker pupa; $\mathrm{NEQ}=$ newly emerged queen; $\mathrm{NEM}=$ newly emerged male; NEW = newly emerged worker; $\mathrm{N}=$ nurse; $\mathrm{F}=$ forager. The graphs show means \pm SEM $(\mathrm{n}=3)$ for methylated DNA $(\mathrm{pg})$ per genomic DNA $(\mu \mathrm{g})$, * semiquantitative estimates since the larval genome is hypermethylated,. Statistical analysis: (A-D) Kruskal-Wallis with a post-hoc Dunn's test, $\mathrm{p}<0.05$; (E) one-tailed Mann-Whitney test, $\mathrm{p}<0.05$.

Worker pupae had a threefold higher methylation content in their DNA when compared to queens and males of the same developmental stage (Figure 1B), and when specifically comparing the two female castes, the global DNA methylation content in pupae of workers was significantly different from that in queens (unpaired $t$-test, $\mathrm{p}<0.05$ ). Thus, the differential DNA methylation content may play a role in the expression of the caste and sex phenotypes of $M$. scutellaris, similar to what has been denoted in honey bees. Analyses of the methylome of honey bee larvae revealed differentially methylated genes related to the regulation of $\mathrm{JH}$ biosynthesis and also showed that splicing is regulated by DNA methylation (Foret et al., 2012; Li-Byarlay et al., 2013). In M. scutellaris, the methylation content increased significantly, almost twofold, as the pupae developed into adult bees, but there were no significant differences among castes or among workers of different age or function in the colonies (foragers and nurses) (Figure 1C,D). Interestingly, similar results were seen in queens and workers of $A$. mellifera, where no differentially methylated regions were found in newly emerged bees (Herb et al., 2012). However, approximately 560 genes in brains of mature adult and 2,390 genes in larval honey bees were identified to be differentially methylated when comparing queens and workers (Lyko et al., 2010; Foret et al., 2012; Herb et al., 2012), suggesting that even without differences in global DNA methylation, specific regions may be differentially methylated also between the castes and sexes of M. scutellaris.
Thus, the transition from nurse to forager of $M$. scutellaris workers may be associated with gene-specific methylation, as observed in honey bees, but this is a hypothesis that remains to be tested by the analysis of actual DNA methylation patterns through bisulfite sequencing.

Gains and losses of DNA methylation have been related to developmental plasticity in the parasitic wasp Nasonia vitripennis (Zwier et al., 2012) and also in the honey bee (Drewell et al., 2014), and our data reported here for M. scutellaris suggest that DNA methylation may be of general importance during the development of this social insect (Figure 1). In mammals, DNMT3 is responsible for de novo methylation activity and is a key driver of global DNA methylation reprogramming (Bestor, 2000), and for A. mellifera, DNMT3 has been convincingly shown to play a critical role in caste differentiation (Kucharski et al., 2008). Hence, similar differences in the enzymatic activity of DNMT3 could be responsible for de novo DNA methylation in M. scutellaris, where global DNA methylation levels drop during the last larval instar (Figure 1A) and then increase with apparently differential dynamics during the pupal stages, before attaining similar levels in the newly emerged adult queens, workers and males (Figure 1B,C).

The variation in global DNA methylation levels during the last larval instar and pupal development presents an interesting potential connection with the divergent $\mathrm{JH}$ and ecdysteroid titers seen in caste development of stingless bees (Hartfelder and Rembold, 1991, Hartfelder et al., 
2006), and alternative splicing of a key gene in the $\mathrm{JH}$ biosynthesis pathway (Vieira et al., 2008) and of the fem gene (Brito et al., 2015) in the genus Melipona. Our results, thus, suggest that epigenetic modifications may represent a link between genotype and environment in the development of the queen or worker phenotypes of Melipona bees, and this hypothesis is supported by the epigenetics data shown in Figure 1 and by previous results in the literature on caste ratios and JH signaling in these bees (Kerr, 1946, 1950, Bonetti et al., 1995).

The presence of DNA methylation on $\mathrm{CpG}$ sites in stingless bees has been predicted from the genome sequence of M. quadrifasciata, and we provide here clear evidence for both DNA methylation and histone modification in M. scutellaris, in relation to sex and caste development and the adult life cycle. The similarity of these highly eusocial bees to honey bees in the degree of sociality should, thus, stimulate further studies on the subfamily Meliponini. Both stingless bees and honey bees are highly eusocial, but they belong to different branches within the clade of corbiculate bees (Cardinal et al., 2010; Hedtke et al., 2013). Furthermore, the Meliponini, with hundreds of species distributed across more than 50 genera (Camargo and Pedro, 2007; Rasmussen and Cameron, 2010) are much more diverse than the honey bees (Apini), represented only by a single genus, Apis, that comprises just seven extant species (Engel, 1999). With respect to the Melipona species mentioned in this study it is worthy of note that Melipona scutellaris Latreille 1811 belongs to the subgenus Michmelia, Melipona interrupta Latreille 1811 to the subgenus Melikerria, and Melipona quadrifasciata Lepeletier 1836 to the subgenus Eomelipona. Eomelipona and Michmelia are sister groups that became separated approxi- mately 16 mya, whereas Melikerria diverged earlier from these two, approximately 20 mya (Rasmussen and Cameron, 2010). Nonetheless, like all Melipona species, they have in common a genetic caste determination mechanism. In several species of the genus Melipona, as well as in other Meliponini, a role for juvenile hormone in queen phenotype induction has been put in evidence, but epigenetic aspects have, so far, only been addressed in M. scutellaris.

\section{Histone modification in Melipona scutellaris sexes and castes}

Here we tested the presence of post-translational modifications on histone $\mathrm{H} 3$ tails. Two distinct, well-established histone post-translational modifications, phosphorylation of threonine 3 on histone H3 (H3T3-P) and mono-methylation of lysine 4 on histone H3 (H3K4-Me), were semiquantitatively analyzed from western blots. We could show that queens have higher levels of both types of histone post-translational modifications when compared to workers of the same age class (Figure 2A), with significant differences in optical densities of the bands (Figure 2B,C; unpaired Student's $t$-test $\mathrm{t}, \mathrm{p}<0.05$ ).

The two types of histone modifications are involved in gene regulation, but they act in distinct ways. H3T3-P is present mainly on heterochromatin domains that are highly represented in mitotically dividing cells, where they were shown to repress gene expression in mammalian cell lines (Varier et al., 2010). In contrast, H3K4-Me is known to act on regulatory sites of the mammalian genome, such as active enhancers (Wu and Ng, 2011; Zhou et al., 2011).

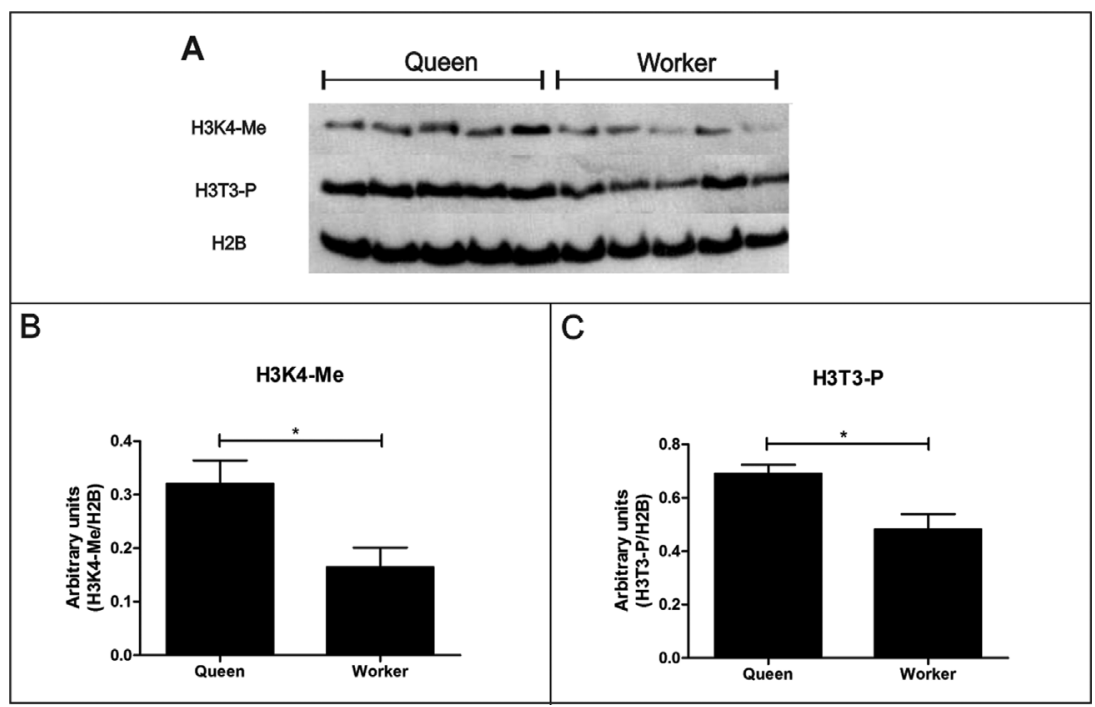

Figure 2 - Histone post-translational modifications in newly emerged queens and workers of Melipona scutellaris. (A) Western blot showing mono-methylation of lysine 4 of histone $\mathrm{H} 3$ (H3K4-Me) and phosphorylation of threonine 3 of histone 3 (H3T3-P); histone H2B (H2B) was used as loading control. (B) Quantification of H3K4-Me bands and (C) Quantification of H3T3-P bands by Image ${ }^{\mathbb{B}}$ software. The y-axes of the graphs represent arbitrary units for intensity of H3K4-Me and H3T3-P bands normalized by H2B band intensity. Bars shown in B and C represent means \pm SEM. Statistical analysis was done by one-tailed, unpaired Student's $t$-tests, $\mathrm{p}<0.001, \mathrm{n}=5$. 


\section{Conclusions}

Our results provide evidence for a composite epigenetic system in Melipona bees, where DNA methylation may control events during the preimaginal developmental stages, while histone post-translational modifications are likely to fine-tune gene expression during the adult life cycle of the bees. In a schematic model (Figure 3) we now propose that in larvae reared under insufficient food conditions (Figure 3A), a global cytosine methylation associated with low levels of $\mathrm{JH}$ production should result in worker development, independent of the individual's genotype condition. The newly emerged workers would then exhibit DNA hypomethylation and hypophosphorylation of histone $\mathrm{H} 3$ tails, leading to subsequent differential gene expres- sion related to the performance of worker tasks (Figure $3 \mathrm{~A})$. With adequate feeding (Figure 3B), the queen genotype larvae/pupae show reduced DNA methylation associated with elevated JH production and likely, activation of other signaling pathways, such as the insulin/insulin-like and TOR pathways. The newly emerged queens would then exhibit hypermethylation and hyperphosphorylation of histone $\mathrm{H} 3$ tails, resulting in the fine tuning of queenspecific gene expression. If larvae have a worker genotype (homozygosity for at least one of the two predicted loci), the adequate feeding conditions alone should not be sufficient to achieve a hypomethylated state of the larval/pupal epigenome, and associated with low $\mathrm{JH}$ production, this would result in worker phenotype individuals (Figure 3B, left side).

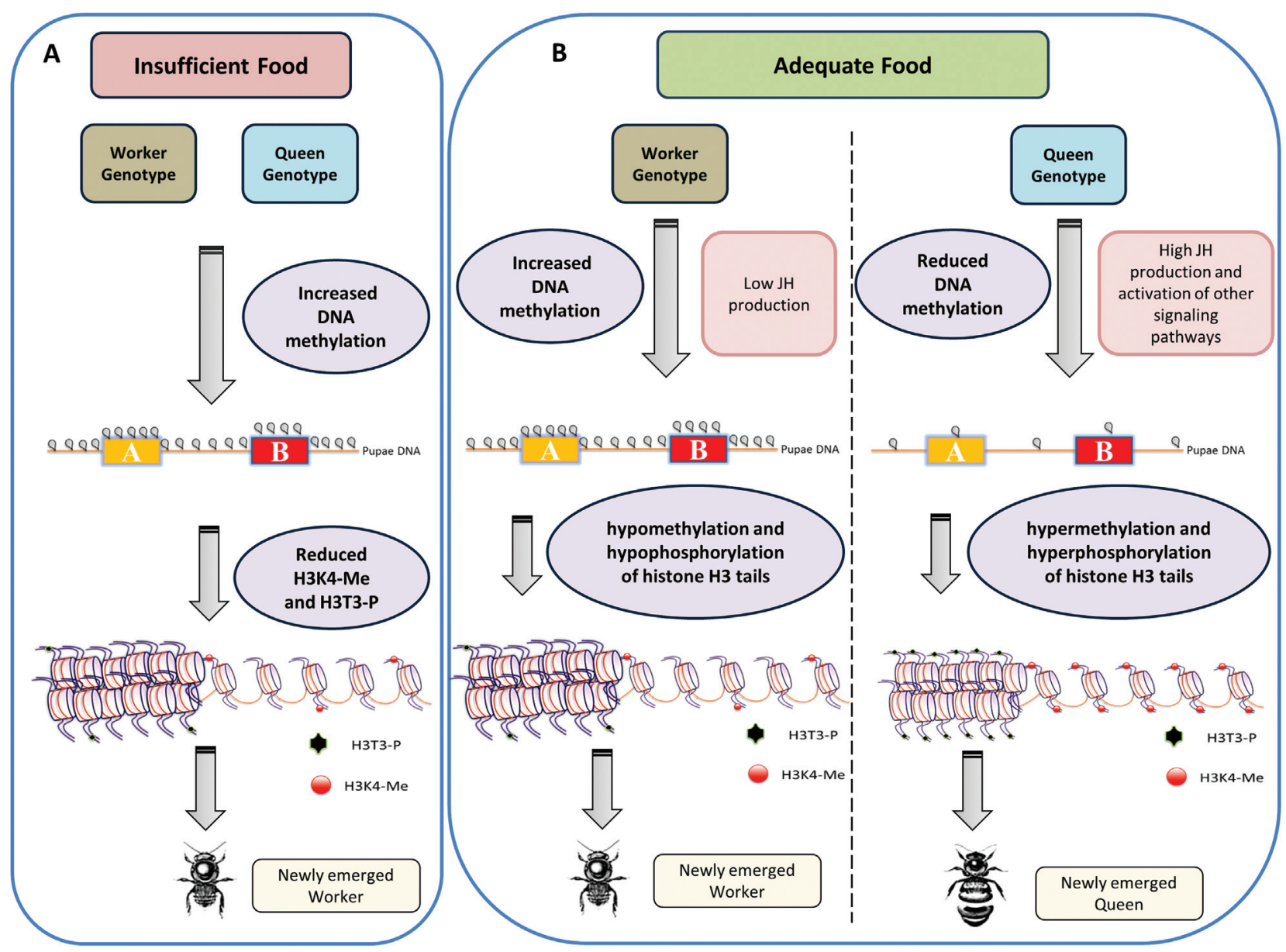

Figure 3 - A schematic model on the interaction of caste genotype (heterozygosity at the two caste loci in queens, or homozygosity for at least one locus in workers), juvenile hormone ( $\mathrm{JH}$ ) production and epigenetic modifications in Melipona scutellaris caste differentiation. (A) Caste differentiation under conditions of insufficient food conditions provided to the larvae. In this case, the genotype bias becomes irrelevant, JH production is low and is associated with DNA hypermethylation during the pupal stage. Subsequently, on adult emergence, DNA is hypomethylated and there is hypophosphorylation of histone H3 tails. (B) Under adequate food conditions the caste genotype comes to play a role, and JH production and possibly other signaling pathways become activated in the queen larvae. The queen genome becomes hypomethylated during the larval-pupal transition, followed by hyperphosphorylation and hypermethylation of histone $\mathrm{H} 3$ tails when the adult queens emerge. In contrast, in worker genotype larvae, JH production is not activated and an increase in DNA methylation occurs at the larval-pupal transition, followed by hypomethylation and hypophosphorylation of histone $\mathrm{H} 3$ tails at the end of preimaginal development. In the adult worker bees, the differences in global methylation then likely favor gene activation related to division of labor (nurses and foragers). Yellow and red boxes with the letters A and B represent the two loci proposed in Kerr's model (Kerr, 1950). 
We finally emphasize the importance of the pioneering studies of Prof. Dr. Warwick E. Kerr, which led him to conclude that caste determination in these stingless bees has a strong genetic component. As a leading geneticist of his time, he formulated this as a two loci/two alleles hypothesis with Mendelian segregation to explain the observed 3:1 segregation of workers and queens in the emerging brood. This eminent Brazilian researcher has brought the stingless bees into the limelight of sociobiology research and paved the way for subsequent studies on the biology of this diverse group of tropical highly eusocial bees, which are important pollinators for crops and native flora.

\section{Acknowledgments}

The authors thank Marcelo Emilio Beletti and Elisson Terêncio Souza (Federal University of Uberlândia) for supplying antibodies and Gislene Almeida Carvalho Zilse (National Institute of Amazonian Research) for providing advice and insights to this manuscript. This work was financially supported by a fellowships from Conselho Nacional de Pesquisa e Desenvolvimento Científico (CNPq, 2013-0349) to CAMCJ and a Fundação de Amparo à Pesquisa do Estado de Minas Gerais grant (FAPEMIG, CBB-APQ-01024-12) to AMB.

\section{References}

Alvarado S, Rajakumar R, Abouheif E and Szyf M (2015) Epigenetic variation in the $E g f r$ gene generates quantitative variation in a complex trait in ants. Nat Commun 6:e6513.

Amaral IM, Moreira Neto JF, Pereira GB, Franco MB, Beletti ME, Kerr WE, Bonetti AM and Ueira-Vieira C (2010) Circulating hemocytes from larvae of Melipona scutellaris (Hymenoptera, Apidae, Meliponini): Cell types and their role in phagocytosis. Micron 41:123-129.

Ayyanath MM, Cutler GC, Scott-Dupree CD, Prithiviraj B, Kandasamy S and Prithiviraj K (2014) Gene expression during imidacloprid-induced hormesis in green peach aphid. Dose Response 12:480-497.

Beig D, Bueno OD and Muller TDJ (1985) Características dos alvéolos de cria e postura de operárias em Melipona quadrifasciata anthidioides Lep. (Hymenoptera, Apidae, Meliponinae). Naturalia 10:75-81.

Bestor TH (2000) The DNA methyltransferases of mammals. Hum Mol Genet 9:2395-2402.

Biewer M, Schlesinger F and Hasselmann M (2015) The evolutionary dynamics of major regulators for sexual development among Hymenoptera species. Front Genet 6:e124.

Bonasio R (2014) The role of chromatin and epigenetics in the polyphenisms of ant castes. Brief Funct Genomics 13:235245.

Bonasio R, Li Q, Lian J, Mutti NS, Jin L, Zhao H, Zhang P, Wen P, Xiang H, Ding Y, et al. (2012) Genome-wide and castespecific DNA methylomes of the ants Camponotus floridanus and Harpegnathos saltator. Curr Biol 22:17551764.
Bonetti AM, Kerr WE and Matusita SH (1995) Effects of juvenile hormones I, II and III, in single and fractionated doses in Melipona bees. Rev Bras Biol 55(Suppl 1):113-120.

Brito DV, Silva CG, Hasselmann M, Viana LS. Astolfi-Filho S and Carvalho-Zilse GA (2015) Molecular characterization of the gene feminizer in the stingless bee Melipona interrupta (Hymenoptera: Apidae) reveals association to sex and caste development. Insect Biochem Mol Biol 66:24-30.

Camargo JMF and Pedro SRM (2007) Meliponini Lepeletier, 1936. In: Moure JS, Urban D and Melo GAR (eds) Catalogue of Bees (Hymenoptera, Apoidea) in the Neotropical Region. Sociedade Brasileira de Entomologia, Curitiba, pp 272-578.

Cardinal S, Straka J and Danforth BN (2010) Comprehensive phylogeny of apid bees reveals the evolutionary origins and antiquity of cleptoparasitism. Proc Natl Acad Sci U S A 107:16207-16211.

Chen H, Rangasamy M, Tan SY, Wang H and Siegfried BD (2010) Evaluation of five methods for total DNA extraction from western corn rootworm beetles. PLoS One 5:e11963.

Corona M, Libbrecht R and Wheeler DE (2016) Molecular mechanisms of phenotypic plasticity in social insects. Curr Opin Insect Sci 13:55060.

Di Paola D, Rampakakis E, Chan MK and Zannis-Hadjopoulos M (2012) Differential chromatin structure encompassing replication origins in transformed and normal cells. Genes Cancer 3:152-176.

Dias J, Bonetti A and Kerr WE (2001) Determinação do número de instares larvais em Melipona scutellaris (Hymenoptera: Apidae). Naturalia 26:257-263.

Dickman MJ, Kucharski R, Maleszka R and Hurd PJ (2013) Extensive histone post-translational modification in honey bees. Insect Biochem Mol Biol 43:125-137.

Drewell RA, Bush EC, Remnant EJ, Wong GT, Beeler SM, Stringham JL, Lim J and Oldroyd BP (2014) The dynamic DNA methylation cycle from egg to sperm in the honey bee Apis mellifera. Development 141:2702-2711.

Engel MS (1999) The taxonomy of recent and fossil honey bees (Hymenoptera: Apidae; Apis). J Hym Res 8:165-196.

Falckenhayn C, Carneiro V, de Mendonça Amarante A, Schmid K, Hanna K, Kang S, Helm M, Dimopoulos G, Fantappié MR and Lyko F (2016) Comprehensive DNA methylation analysis of the Aedes aegypti genome. Sci Rep 6:36444.

Feliciello I, Parazajder J, Akrap I and Ugarkovic D (2013) First evidence of DNA methylation in the insect Tribolium castaneum: Environmental regulation of DNA methylation within heterochromatin. Epigenetics 8:534-541.

Foret S, Kucharski R, Pellegrini M, Feng S, Jacobsen SE, Robinson GE and Maleszka R (2012) DNA methylation dynamics, metabolic fluxes, gene splicing, and alternative phenotypes in honey bees. Proc Natl Acad Sci U S A 109:4968-4973.

Gabor Miklos GL and Maleszka R (2011) Epigenomic communication systems in humans and honey bees: From molecules to behavior. Horm Behav 59:399-406.

Glastad KM, Hunt BG and Goodisman MA (2015) DNA methylation and chromatin organization in insects: Insights from the ant Camponotus floridanus. Genome Biol Evol 7:931942.

Hartfelder K and Rembold R (1991) Caste-specific modulation of juvenile hormone-III content and ecdysteroid titer in postembryonic development of the stingless bee Scaptotrigona 
postica depilis. J Comp Physiol B Biochem Syst Environ Physiol 160:617-620.

Hartfelder K, Makert GR, Judice CC, Pereira GAG, Santana WC, Dallacqua R and Bitondi MMG (2006) Physiological and genetic mechanisms underlying caste development, reproduction and division of labor in stingless bees. Apidologie 37:144-163.

Hartfelder K, Guidugli-Lazzarini KR, Cervoni MS, Santos DE and Humann FC (2015) Old threads make new tapestry - rewiring of signaling pathways underlies caste phenotypic plasticity in the honey bee, Apis mellifera L. Adv Insect Physiol 48:1-36.

Hedtke SM, Patiny S and Danforth BN (2013) The bee tree of life: A supermatrix approach to apoid phylogeny and biogeography. BMC Evol Biol 13:138.

Herb BR, Wolschin F, Hansen KD, Aryee MJ, Langmead B, Irizarry R, Amdam GV and Feinberg AP (2012) Reversible switching between epigenetic states in honeybee behavioral subcastes. Nat Neurosci 15:1371-1373.

Jarau S, van Veen JW, Twele R, Reichle C, Gonzales EH, Aguilar I, Francke W and Ayasse M (2010) Workers make the queens in Melipona bees: Identification of geraniol as a caste determining compound from labial glands of nurse bees. J Chem Ecol 36:565-569.

Kapheim KM, Pan H, Li C, Salzberg SL, Puiu D, Magoc T, Robertson HM, Hudson ME, Venkat A, Fischman BJ, et al. (2015) Genomic signatures of evolutionary transitions from solitary to group living. Science 348:1139-1143.

Kerr WE (1946) Formação de castas no gênero Melipona (Illiger, 1806) - Nota prévia. Anais Esc Sup Agric "Luiz de Queiroz" 3:299-312.

Kerr WE (1950) Genetic determination of castes in the genus Melipona. Genetics 35:143-152.

Kerr WE and Nielsen RA (1966) Evidences that genetically determined Melipona queens can become workers. Genetics 54:859-866.

Kucharski R, Maleszka J, Foret S and Maleszka R (2008) Nutritional control of reproductive status in honeybees via DNA methylation. Science 319:1827-1830.

Kunert N, Marhold J, Stanke J, Stach D and Lyko F (2003) A Dnmt2-like protein mediates DNA methylation in Drosophila. Development 130:5083-5090.

Li-Byarlay H, Li Y, Stroud H, Feng S, Newman TC, Kaneda M, Hou KK, Worley KC, Elsik CG, Wickline SA, et al. (2013) RNA interference knockdown of DNA methyl-transferase 3 affects gene alternative splicing in the honey bee. Proc Natl Acad Sci U S A 110:12750-12755.

Lockett GA, Helliwell P and Maleszka R (2010) Involvement of DNA methylation in memory processing in the honey bee. Neuroreport 21:812-816.

Lyko F, Ramsahoye BH and Jaenisch R (2000) DNA methylation in Drosophila melanogaster. Nature 408:538-540.

Lyko F, Foret S, Kucharski R, Wolf S, Falckenhayn C and Maleszka R (2010) The honey bee epigenomes: Differential methylation of brain DNA in queens and workers. PLoS Biol 8:e1000506.

Olkhov-Mitsel E and Bapat B (2012) Strategies for discovery and validation of methylated and hydroxymethylated DNA biomarkers. Cancer Med 1:237-260.
Rasmussen C and Cameron SA (2010) Global stingless bee phylogeny supports ancient divergence, vicariance, and long distance dispersal. Biol J Linn Soc 99:206-232.

Shi YY, Huang ZY, Zeng ZJ, Wang ZL,Wu XB and Yan WY (2011) Diet and cell size both affect queen-worker differentiation through DNA methylation in honey bees (Apis mellifera, Apidae). PLoS One 6:e18808.

The Honey Bee Genome Sequencing Consortium (2006) Insights into social insects from the genome of the honeybee Apis mellifera. Nature 443:931-949.

Tribolium Genome Sequencing Consortium, Richard S, Gibbs RA, Weinstock GM, Brown SJ, Denell R, Beeman RW, Brown SJ, Bucher G, Friedrich M, et al. (2008) The genome of the model beetle and pest Tribolium castaneum. Nature 452:949-955.

Tweedie S, Ng HH, Barlow AL, Turner BM, Hendrich B and Bird A (1999) Vestiges of a DNA methylation system in Drosophila melanogaster? Nat Genet 23:389-390.

Varier RA, Outchkourov NS, de Graaf P, van Schaik FM, Ensing HJ, Wang F, Higgins JM, Kops GJ and Timmers HT (2010) A phospho/methyl switch at histone $\mathrm{H} 3$ regulates TFIID association with mitotic chromosomes. EMBO J 29:39673978.

Velthuis HHW (1976) Environmental, genetic and endocrine influences in stingless bee caste determination. In: Lüscher M (ed) Phase and Caste Determination in Insects. Pergamon Press, Oxford, pp 63-70.

Vieira CU, Bonetti AM, Simoes ZL, Maranhão AQ, Costa CS, Costa MC, Siquieroli AC and Nunes FM (2008) Farnesoic acid O-methyl transferase (FAMeT) isoforms: Conserved traits and gene expression patterns related to caste differentiation in the stingless bee, Melipona scutellaris. Arch Insect Biochem Physiol 67:97-106.

Wang Y, Jorda M, Jones PL, Maleszka R, Ling X, Robertson HM, Mizzen CA, Peinado MA and Robinson GE (2006) Functional $\mathrm{CpG}$ methylation system in a social insect. Science 314:645-647.

Weiner SA, Galbraith DA, Adams DC, Valenzuela N, Noll FB, Grozinger CM and Toth AL (2013) A survey of DNA methylation across social insect species, life stages, and castes reveals abundant and caste-associated methylation in a primitively social wasp. Naturwissenschaften 100:795799.

Wenseleers T and Ratnieks FL (2004) Tragedy of the commons in Melipona bees. Proc Biol Sci 271(Suppl 5):S310-S312.

Wenseleers T, Ratnieks FL and Billen J (2003) Caste fate conflict in swarm-founding social Hymenoptera: An inclusive fitness analysis. J Evol Biol 16:647-658.

Wu Q and Ng HH (2011) Mark the transition: Chromatin modifications and cell fate decision. Cell Res 21:1388-1390.

Zhou VW, Goren A and Bernstein BE (2011) Charting histone modifications and the functional organization of mammalian genomes. Nat Rev Genet 12:7-18.

Zwier MV, Verhulst EC, Zwahlen RD, Beukeboom LW and van de Zande L (2012) DNA methylation plays a crucial role during early Nasonia development. Insect Mol Biol 21:129138.

\section{Associate Editor: Igor Schneider}

License information: This is an open-access article distributed under the terms of the Creative Commons Attribution License (type CC-BY), which permits unrestricted use, distribution and reproduction in any medium, provided the original article is properly cited. 